\title{
Challenges of implementing Building Information Modeling (BIM) in the Construction Industry
}

\section{SIGRADI2018 TECHNOPOLITICAS \\ xxii congresso da sociedade iberoamericana de gráfica digital 22th conference of the iberoamerican society of digital graphics 07|08|09|novembro|2018 iau usp | são carlos | sp br}

\author{
Beatriz Vonsovicz Zeglin \\ UFSC | Brazil | beatrizzeglin@gmail.com
}

Angélica Mufato Reis

UFSC | Brazil | angelicamufato@gmail.com

Lizandra Garcia Lupi Vergara

UFSC | Brazil | lizandravergara@gmail.com

\begin{abstract}
Building Information Modeling (BIM) has provided a new level of technology and efficiency to the construction industry, making production processes more integrated and proficient. This type of innovation is a complex implementation process with many gaps that must be addressed. This article highlights the challenges of implementing BIM, discussing strategies to transform this scenario. The methodology is developed from synthesizing the literature and analyzing semistructured interviews with architects. The results, obtained through content analysis, are explained by the subdivision of the implementation challenges in the following categories: human factor, management, policy, market, and technology.
\end{abstract}

Keywords: Building Information Modeling; BIM; Challenges; Implementation.

\section{INTRODUÇÃO}

A indústria da construção civil tem buscado formas para melhorar sua eficiência produtiva e entregar um produto com mais qualidade e sustentável a quem o utiliza. Nesse contexto, o BIM - Building Information Modeling - surge como um conjunto de políticas, processos e tecnologias de interação que geram uma metodologia que integra profissionais das áreas de Arquitetura, Engenharia e Construção (AEC) na elaboração de um modelo virtual único, que contempla todo o ciclo de vida de uma edificação (Succar, 2009).

Tal ferramenta tecnológica é capaz de melhorar o produto, entregando mais valor ao cliente, e otimizar os processos da construção, a partir da modelagem digital do edifício, atribuindo-lhe informações (Sacks et. al, 2018). Quando concluído, o modelo gerado contém a geometria e os dados relevantes para apoiar as atividades de fabricação, construção e aquisição necessárias para realizar a construção. Implementado de forma adequada, o BIM facilita a integração do processo de concepção e de construção, o que resulta na melhoria da qualidade dos edifícios, na otimização dos custos e confiabilidade dos dados de planejamento (Eastman et al.,2014).

Ainda nos estágios iniciais, a implantação dessa tecnologia irá modificar profundamente a forma como o ser humano percebe e interage com o meio ambiente construído (Manzione, 2013). Por caracterizar um processo tecnológico disruptivo, além de assimilar novas ferramentas tecnológicas e aprender a trabalhar colaborativamente, aos profissionais que quiserem trabalhar com BIM serão impostos muitos outros desafios que permeiam esse processo.

Buscou-se, portanto, contribuir para o entendimento dos desafios impostos aos arquitetos que atravessam o processo de implementação do BIM, através da análise de conteúdo de 15 entrevistas semiestruturadas realizadas com profissionais com reconhecida atuação no mercado de Florianópolis.

\section{METODOLOGIA}

Este artigo se caracteriza como uma pesquisa qualitativa, e quanto à natureza do seu objetivo é uma pesquisa exploratória. Além da revisão de literatura a respeito do estado da arte da temática, buscou-se compreender os desafios existentes na implementação do BIM. Para tanto, foram realizadas entrevistas semiestruturadas com 15 arquitetos que passaram pelo processo de implementação do BIM. Utilizou-se um roteiro de entrevista (Tabela 01) composto por dez questões abertas, de forma a permitir o aprofundamento em tópicos de maior interesse para a discussão.

As respostas foram registradas e transcritas em sua totalidade para preparar os dados para análise. Para tratamento dos dados, adotou-se a abordagem da análise de conteúdo dos resultados obtidos. A partir disso, códigos foram atribuídos a palavras, frases e segmentos dentro dos dados relevantes para a questão de pesquisa (Bardin, 2009). Esses códigos foram então categorizados em temas relevantes e tabulados a partir do software excel. 
Tabela 1: Roteiro das entrevistas semiestruturadas realizadas.

\begin{tabular}{l}
\hline Roteiro para entrevistas \\
\hline Nome: \\
Idade: \\
Tempo de experiência profissional: \\
Tempo de utilização do BIM: \\
Extensão do uso do BIM (3D a 10D): \\
Como foi a migração do desenvolvimento dos projetos em \\
CAD para o processo BIM? \\
Como se desenvolve o processo de trabalho - internos e \\
interempresariais? \\
Com relação a infraestrutura necessária para a operação, \\
como você avalia a estrutura tecnológica necessária \\
implantada bem como o treinamento e aculturamento dos \\
usuários? \\
Como está o preparo dos profissionais frente a esse \\
processo? \\
Como os clientes interpretam e demandam projetos em \\
BIM?
\end{tabular}

A pesquisa foi aprovada pelo Comitê de Ética em Pesquisas com Seres Humanos da Universidade Estadual de Santa Catarina, parecer número 2.390.977. Os participantes assinaram o Termo de Consentimento Livre e Esclarecido, concordando em participar da amostra como voluntários, de forma confidencial e anônima.

\section{RESULTADOS}

\section{MIGRAÇÃO DO CAD PARA O BIM}

$A$ indústria da $A E C$ há muito tempo busca técnicas para diminuir o custo do projeto, aumentar a produtividade e a qualidade e reduzir o tempo de entrega do projeto. A modelagem da informação da construção oferece o potencial para alcançar esses objetivos (Azhar et al., 2008). A substituição de uma metodologia CAD 2D ou 3D pelo BIM, entretanto, envolve aspectos que vão além da aquisição de software, hardware e treinamento. É necessária uma mudança dos aspectos gerais da empresa, além de conhecimento da tecnologia e o correto desenvolvimento de um plano de implantação prévio (Eastman et al., 2014).

A busca pela implantação dessa nova tecnologia é justificada, dentre outros motivos, pela necessidade de se aumentar a produtividade dentro de toda cadeia de valor. Nesse sentido, empresas e profissionais do setor estão explorando novas formas de se desenvolver e gerenciar os projetos, buscando maior eficiência e eficácia (Cao et al., 2015). Assim, o aspecto mais abordado pelos entrevistados na justificativa de migração para o BIM foi fundamentada pela necessidade de aumento de produtividade (60\%) conforme mostra a Figura 1.

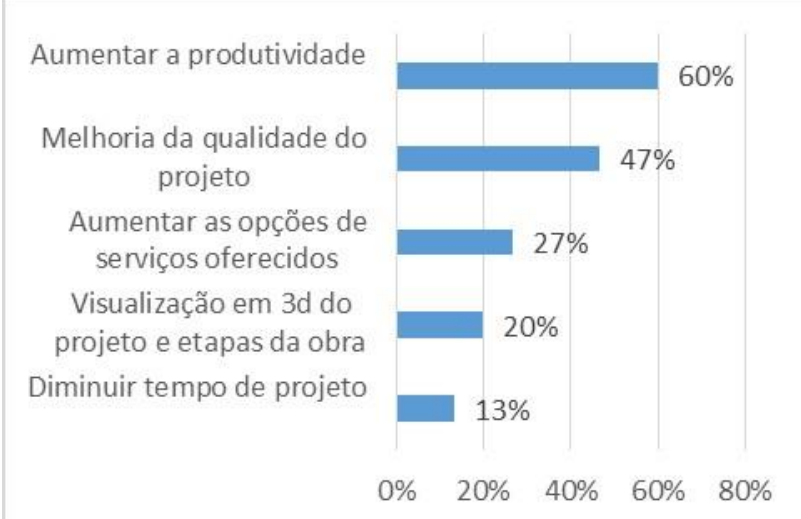

Figura 1: Motivações de migração de CAD para BIM. Fonte: Os autores, 2017

O BIM possui grande influência no aumento de produtividade em todo ciclo de vida da edificação, uma vez que facilita as alterações de projeto pela visualização das interferências geométricas e maior agilidade nas representações visuais. Além disso, escopos de trabalho podem ser facilmente isolados e definidos, sistemas, montagens e sequências construtivas podem ser visualizadas, assim como documentos de construção como desenhos, detalhes de compras e outras especificações podem ser facilmente inter-relacionados (Khemlani et al., 2009).

O BIM pode ser visto como um processo virtual que abrange todos os aspectos, disciplinas e sistemas de uma instalação dentro de um único modelo virtual, permitindo que todos os membros da equipe (proprietários, arquitetos, engenheiros, contratados, subcontratados e fornecedores) colaborem com mais precisão e eficiência do que nos processos tradicionais. Com as alterações dinâmicas, os membros da equipe estão constantemente refinando e ajustando de acordo com as especificações e as mudanças de projeto, a fim de garantir que o modelo seja o mais preciso possível (Carmona \& Irwin 2007). Tudo isso faz com que, dentre outros motivos, o produto final tenha mais qualidade, fator esse que apareceu como segundo mais citado pelos entrevistados (47\%).

Outros fatores destacados pelos arquitetos entrevistados foram: o aumento das opções de serviços oferecidos (27\%), a possibilidade de visualização em 3D do projeto e das etapas da obra (20\%) e, por fim, a diminuição do tempo de projeto (13\%), principalmente pautado pela exigência dos contratantes de submeter 0 projeto rapidamente aos órgãos públicos de aprovação e ao alto índice de correções advindas das restrições impostas pelas demais disciplinas, após a compatibilização de projeto.

\section{DESAFIOS PARA IMPLEMENTAÇÃO DO BIM}

Os constantes desenvolvimentos na indústria da construção estabeleceram novos desafios para a atividade colaborativa dentre todos os envolvidos na cadeia produtiva. Com o BIM, o projeto e a construção não são mais apenas um processo passo a passo, mas uma rede complexa de sistemas de atividades, onde cada envolvido possui interesses, motivos e perspectivas parcialmente diferentes em relação ao objeto da atividade de construção (Kerosuo et. al, 2015). 
A identificação dos desafios enfrentados na implementação do BIM permite compreendê-los e gerenciá-los: ao perceber os fatores que afetam essa implementação bem-sucedida, as organizações saberão quais são os esforços de melhoria e onde tais esforços devem ser focados para obter melhores resultados.

Com base nas respostas das entrevistas e na literatura, a presente pesquisa dividiu os desafios em quatro categorias, as quais se relacionam a: fator humano, gestão, política e mercado, e tecnologia, conforme segue.

\section{DESAFIOS RELACIONADOS AO FATOR HUMANO}

Segundo $47 \%$ dos entrevistados, uma das grandes transformações que acompanham esse novo processo tecnológico é a mudança da composição de trabalho com respeito às habilidades técnicas. Nesse cenário, contratação de profissionais mais qualificados (consequentemente melhor remunerados) representa 0 principal desafio para implementação do BIM dentro da categoria fator humano, conforme mostra a Figura 2.

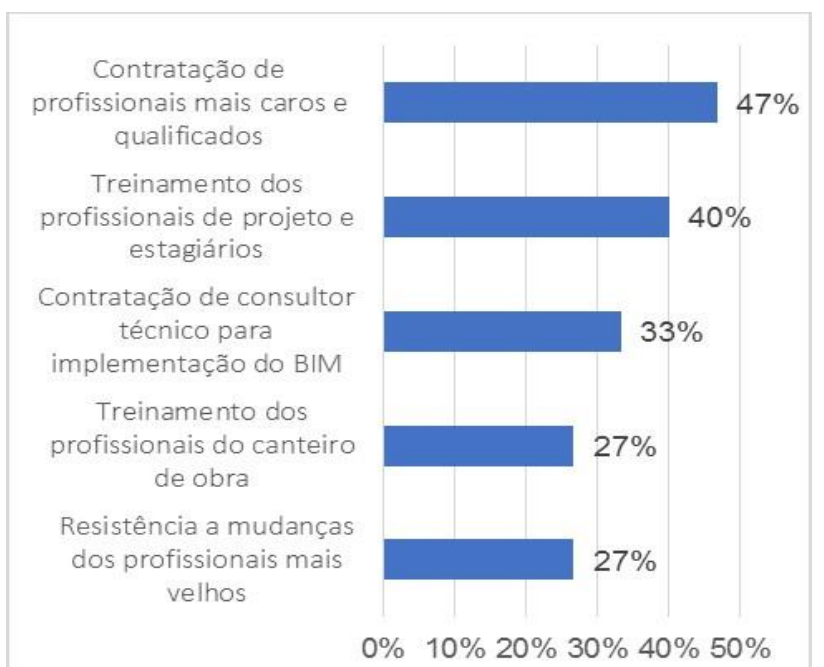

Figura 2: Desafios relacionados ao fator humano. Fonte: Os autores, 2017

Eastman et al. (2014) coloca que, devido ao fato da documentação de projetos ser automatizada com o BIM, projetistas juniores e estagiários são cada vez menos requisitados. Como o foco principal passa a ser o projeto é requerida mais dedicação por parte dos gestores de projeto e arquitetos projetistas mais experientes, como podemos observar na Tabela 2.

Tabela 2: Horas gastas no projetos pré-BIM e pós-BIM. Fonte: EASTMAN et al., 2014

\begin{tabular}{lrcc}
\hline Classe Profissional & Pré BIM & Pós BIM & Variação \\
\hline Principal & 32 & 32 & $0 \%$ \\
Gestor de Projetos & 128 & 192 & $33 \%$ \\
Arquiteto Projetista & 192 & 320 & $40 \%$ \\
Arquiteto & 320 & 192 & $-67 \%$ \\
Estagiário de arquitetura & 320 & 96 & $-233 \%$ \\
Total & 992 & 832 & $-19 \%$ \\
\hline
\end{tabular}

Além disso, a construção virtual do edifício exige que o projeto arquitetônico esteja melhor resolvido, o arquiteto E2 coloca que "[...] voltou para o arquiteto aquilo que precisaria ser definido por ele. Os projetistas quase não vão mais para a obra, pois acostumaram-se com o profissional no local que acaba resolvendo. Com o BIM, acaba voltando para 0 arquiteto projetista a responsabilidade de fazer um projeto com qualidade e esse profissional tem um custo maior."

O segundo item mais abordado (40\%) é a necessidade de treinamento dos projetistas e estagiários para esse novo processo. Nesse contexto, os currículos das Universidades precisam ser revistos para essa nova realidade de mercado, pois os estudantes estão adquirindo conhecimentos obsoletos em sua prática futura e não estão sendo preparados para trabalhar em ambientes digitais integrados (Forgues et al., 2011). O arquiteto E15 coloca que "[...] as Escolas assumem o papel de agentes condutores da transformação. Falta treinamento em BIM no ensino superior e essa curva de aprendizado é lenta" e, nas palavras de E7, "[...] as escolas precisam estar mais antenadas com as novas tecnologias, pois recebemos estagiários sem nenhum tipo de contato com a tecnologia e com a realidade de obra", - que acaba gerando essa lacuna entre o que é aprendido nas Universidades e o que é exigido no mercado de trabalho.

A necessidade de encontrar e contratar um consultor técnico para implementação da tecnologia foi o terceiro desafio que mais apareceu (33\%) sendo que, para todos os escritórios a questão chave na condução da implantação - como coloca E3 - está em "[...] implementar a tecnologia sem travar a produção interna de projeto. Para que toda essa curva de aprendizagem do BIM não atrapalhasse o dia a dia do escritório fizemos a transição com um projeto piloto pequeno antes de expandir para todos os demais projetos. É um processo lento".

Por fim, o quarto aspecto mais citado dentro do fator recursos humanos foi a necessidade do treinamento dos profissionais do canteiro de obra assim como a resistência a mudanças dos profissionais mais velhos $(27 \%)$. No que diz respeito ao treinamento dos profissionais do canteiro, E1 ressalta que "[...] como a ferramenta também antecipa os erros visualizados em obra, é possível criar inúmeros detalhamentos e vistas para a equipe de obra conseguir melhor visualizar as possibilidades construtivas. Os profissionais da obra deveriam estar treinados para essa nova realidade, mas isso ainda não ocorre. O software navisworks, por exemplo, já mostra todo o planejamento de obra com uma interface bem visual, mas a obra ainda não se apropria bem desse recurso".

Em relação à resistência dos profissionais mais velhos, a implantação de novas tecnologias exige a adoção de novas práticas. Tais líderes de equipe possuem décadas de experiência com clientes, desenvolveram métodos próprios, possuem familiaridade com as ferramentas e procedimentos realizados (Eastman et al., 2014). Além disso, tais usuários muitas vezes não enxergam a necessidade de migração para essa tecnologia, pois acreditam que a tecnologia CAD os atende bem (Yan \& Damian, 2008).

\section{DESAFIOS RELACIONADOS Á GESTÃO}

$O$ desafio mais relatado pelos entrevistados foi a necessidade de mudança na cultura de processo e

3 
gestão de projetos (53\%). A utilização do modelo BIM no desenvolvimento de projetos altera não só o fluxo de informações, mas também as interfaces entre os projetistas e o coordenador de projetos, apresentando-se como uma modificação na maneira de se encarar o próprio processo. Nas palavras do entrevistado E7, na tecnologia BIM "[...] o projeto deixa de ser entendido no formato linear - com as caixinhas das etapas separadas - e passa a ser entendido com um grande hub de informações". Para que isso de desenvolva, E14 coloca que "[...] foi preciso redesenhar todos os processos e métodos de trabalho, reorganização de equipes e definição de novas lideranças e responsabilidades. E as novas demandas exigem novas dinâmicas dentro do escritório".

Tal mudança na cultura de processo e gestão de projeto leva, necessariamente, a uma necessidade de mudança no escopo do contrato em BIM, sendo esse o segundo item mais colocado pelos entrevistados (47\%) conforme mostra a Figura 3. O arquiteto acaba assumindo, muitas vezes, o papel de gestor do projeto, e isso ainda não está bem claro nos contratos. E15 complementa que "[...] estamos responsáveis pela precisão, análise e compatibilização, mas isso ainda necessita de melhores definições contratuais e, parte disso, pode ser solucionada com um novo manual de escopo de projeto".

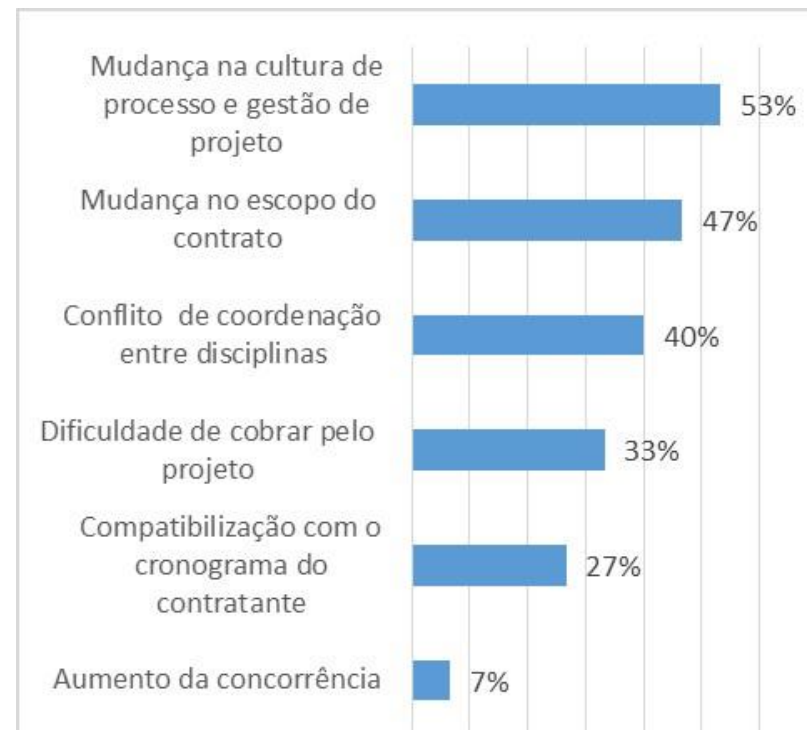

$0 \% 10 \% 20 \% 30 \% 40 \% 50 \% 60 \%$

Figura 3:Desafios relacionados à gestão. Fonte: Os autores, 2017.

Como é vasta a extensão do uso do BIM, a primeira definição é balizar os propósitos do modelo, a fim de atender os requisitos requeridos. Adotar o nível de detalhe mais adequado para cada situação requer experiência de todo time do projeto. O objetivo do modelo tem quer ser claramente entendido para gerar especificações que, quando atendidas, darão origem a um modelo que é realista o suficiente para servir ao seu propósito como uma simulação (Kymmell, 2008).

Diante dos empecilhos relacionados aos aspectos de colaboração entre os agentes, o American Institute of Architects (AIA) propôs um modelo contratual para projetos integrados, o chamado Integrated Project
Delivery (IPD), uma abordagem de entrega de projetos para integrar as pessoas, sistemas e estruturas e práticas de negócios em um processo colaborativo para reduzir o desperdício e otimizar a eficiência em todas as fases do ciclo de vida do projeto (Glick \& Guggemos 2009). Ela fomenta a relação colaborativa dos agentes do empreendimento por meio do compartilhamento dos resultados entre os participantes.

O conflito de coordenação entre disciplinas apareceu como terceiro item mais citado (40\%). Como o BIM coloca a colaboração entre todos agentes de projeto como algo inerente ao processo, deverá ampliar a necessidade de se estruturar os dados e informações gerados durante todo o projeto, ressaltando a importância de se definir claramente o fluxo de informações e protocolos que orientem os processos envolvidos (Kassem et al., 2015).

Enquanto essas questões não estão bem delineadas, acabam existindo conflitos na coordenação entre disciplinas. E3 expõe que "[...] cabe ao profissional responsável pela compatibilização identificar, analisar e julgar as questões que devem ser tratadas e levadas para as discussões em reuniões de compatibilização e ocorre que, após isso, é que "existe uma dificuldade de balizamento sobre qual disciplina irá fazer a adequação do projeto ao se detectar uma interferência". E15 complementa: "[...] ninguém quer ter retrabalhos em função da detecção de inconsistências".

Outro fator de destaque dentro da categoria gestão foi a dificuldade de vender os benefícios de se contratar um projeto em BIM (33\%), já que os honorários dos profissionais são maiores. Segundo Eastman et al. (2014), embora a elaboração de um modelo BIM possa custar mais que um desenho CAD, a escolha daquele é justificada pelas vantagens subsequentes atribuídas, como o planejamento de construção e design detalhado para mecânica, hidros sanitário, elétrica e estrutura, revisões de design, análises, simulações, etc. Nesse ponto foi percebido claramente as diferenças entre os contratantes tipo pessoa física e jurídica. E7 coloca que "[...] as construtoras conseguem perceber e materializar melhor essa economia de quantitativo, de cronograma de obra, diminuição de retrabalhos e incompatibilidades" enquanto que, conforme E8, "[...] o cliente tipo pessoa física até visualiza melhor a construção virtual, analisa custos e performance de sustentabilidade do projeto, mas ainda tem menos disposição para pagar mais por um projeto em BIM.

O quinto aspecto citado, foi o desafio da compatibilização com o cronograma do contratante $(27 \%)$. O uso da tecnologia BIM exige mais esforço nas fases iniciais de projeto, conforme a Figura 4, e os clientes estão acostumados com prazos mais enxutos para submeter 0 projeto para os órgãos de aprovação.

E1 elucida bem essa questão: "[...] os softwares exigem que você já defina o que é uma parede, pois ela não é apenas uma representação visual de dois traços, e sim uma composição de insumos compostos por diferentes materiais e espessuras...E como ela é feita? Como ela é encaixada? Isso traz o projeto para a realidade, como ele vai ser e funcionar. Por isso que o estudo preliminar tem um nível mais avançado de projeto. As decisões que 
normalmente se concentram no projeto executivo serão antecipadas para as fases iniciais de projeto. $O$ entrevistado E12 complementa que "[...] como todos os detalhes são definidos já na modelagem inicial, o tempo do estudo preliminar fica mais dilatado e, geralmente, incompatível com o tempo determinado pelo cliente".

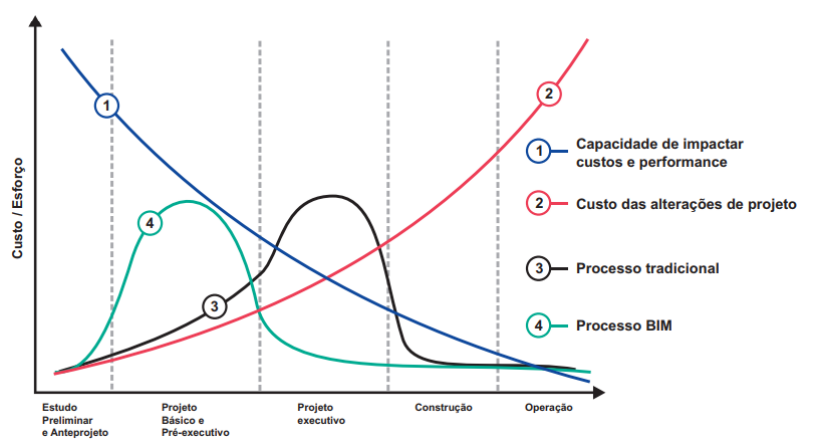

Figura 4: Curva de esforço (Patrick Macleamy Curve). Fonte: AsBEA, 2015.

Por fim, o último aspecto abordado foi o aumento da concorrência com projetistas de outros estados e países (7\%), os quais já saem na frente por conta do domínio da tecnologia. Nesse sentido, o arquiteto E13 alerta que "[...] a concorrência agora é global. Ou corremos atrás do conhecimento ou vamos perder espaço para os escritórios estrangeiros. Esse movimento já está acontecendo com as maiores incorporadoras do País e, sem dúvida, é válido para todos os fornecedores de serviços de projeto da cadeia da construção civil".

\section{DESAFIOS RELACIONADOS À POLÍTICA E MERCADO}

O aspecto mais citado pelos entrevistados foi a falta de um protocolo BIM (40\%). Muitos guias, cadernos dentre outros foram feitos por diversos setores no Brasil destacam-se a Coletânea Implementação do BIM, da Câmara Brasileira da Indústria da Construção (CBIC) de 2017, o Guia de Boas Práticas em BIM, da Associação Brasileira dos Escritórios de Arquitetura (AsBEA) de 2015, e os Guias BIM, da Agência Brasileira de Desenvolvimento Industrial (ADBI) de 2017 - para alavancar a disseminação da tecnologia. Nesse contexto, o Estado de Santa Catarina é lembrado pelo entrevistado E8 que coloca que "[...]o Estado é precursor desse movimento ao ser o primeiro a adotar o Openbim e a fazer o Caderno de Apresentação de projetos em BIM, desenvolvido pelo Governo de Santa Catarina".

Além disso, a adequação a novas demandas exigidas pelo mercado também apareceu em segundo lugar (27\%). Um dos grandes impactos foi a recente revisão da nova norma de desempenho das edificações (NBR 15575-1), a qual trouxe a exigência de mensuração do desempenho global da edificação e o BIM entra com a simulação da performance do modelo. Aksamija (2012) aponta que uma das grandes barreiras na utilização de BIM para análises térmicas, por exemplo, é exatamente o compartilhamento e consistência de informações ao se exportar dados de um software para outro.

Além disso, Silva et al (2014) defendem que o método computacional exigido pela norma não contempla todos os parâmetros necessários para uma análise acurada
BIM em alguns softwares computacionais, como o Energy Plus. Além de algumas revisões necessárias na norma, para que as simulações sejam mais assertivas, o entrevistado E13 coloca que serão necessárias "[...] informações detalhadas dos produtos, tais como dimensões e características físicas, a divulgação de dados relativos aos seus desempenhos, à aplicabilidade e até à manutenção. E8 complementa sobre a necessidade dos "[...] dados para conseguir atender também as demandas de uso e operação para atendimento de todo o ciclo de vida da edificação".

Em terceiro lugar aparecem falta de disseminação do conhecimento das normas técnicas sobre o BIM. O arquiteto E10 pontua que "[...] a ABNT normatizou através do Sistema de classificação da informação da construção, mas faltam cursos e divulgação da norma em vigor". A norma disponibiliza um sistema de classificação de informações codificado padronizado, que facilita muito a implementação de vários usos de BIM, viabilização do trabalho colaborativo na indústria da construção civil brasileira.

Outro ponto que apareceu nos resultados é que os órgãos públicos poderiam ser mais ágeis nas análises dos projetos se dominassem o uso da tecnologia (13\%), conforme mostra a Figura 5. E13 coloca que "[...] Hoje existem softwares disponíveis para parametrizar as análises dos projetos em BIM, mas os órgãos públicos de análise ainda estão muito atrasados nesse sentido".

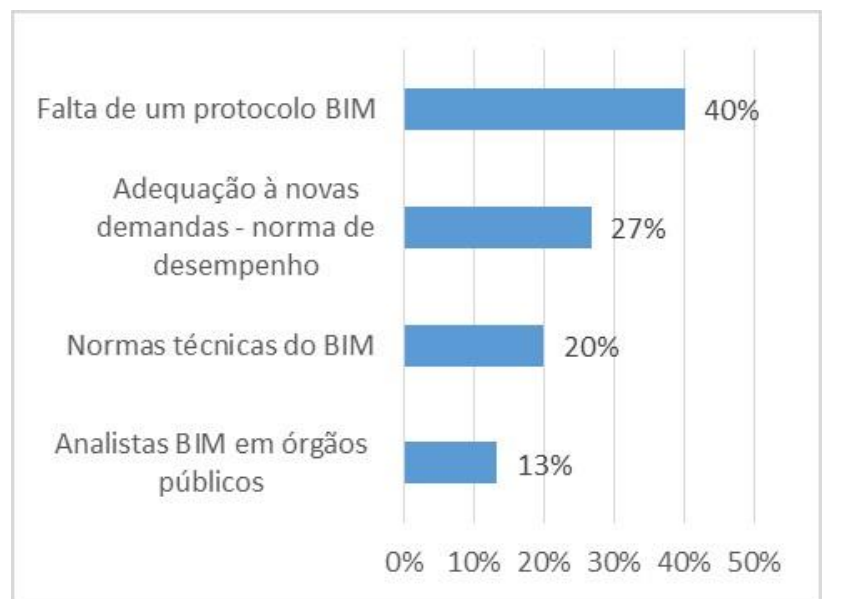

Figura 5: Desafios relacionados à política e mercado. Fonte: Os autores, 2017.

\section{DESAFIOS RELACIONADOS À TECNOLOGIA}

Alto investimento na tecnologia BIM - seja em hardware, software, rede interna (servidor) e externa (internet) - foi o aspecto mais citado dentre os entrevistados (67\%). O arquiteto E1 ressalta que a tecnologia demanda por computadores com maior capacidade de processamento, pois "[...] com software (revit) utilizado não é possível fazer um downgrade na versão, ou seja, não tem como salvar numa versão anterior. Isso obriga todos os projetistas a utilizarem a versão mais recente e, por isso, exigindo bons computadores para poder suportar isso". Com isso, E2 complementa que "[...] a curva de obsolescência fica exponencial e, quando precisamos abrir um arquivo com um computador menos potente tem que ter uma paciência, acaba sendo muito improdutivo. Como trabalhamos em rede, o dia que a rede está lenta fica caótica a situação". 
O segundo item mais abordado foi a falta de biblioteca e informações dos produtos brasileiros (53\%). Nesse contexto, E1 coloca que "[...] no que tange as análises de desempenho e sustentabilidade, existe uma dificuldade que, além de ser difícil de operar e demandar um tempo e esforço, as informações dos produtos brasileiros não são tão claras. Se você precisar alimentar no programa para obter indicadores, você não consegue tão facilmente pelas empresas. Por exemplo o tijolo, produzido em Tubarão, não tem o coeficiente de transmitância, e isso teria que ser alimentado para obter-se veracidade nas informações". Assim, E15 complementa que, "[...] para que os desenhos virtuais possam de fato representar a realidade de uma obra, a criação de bibliotecas de componentes se torna essencial e isso ainda está bem atrasado no Brasil".

O desafio da interoperabilidade aparece em terceiro lugar dentro dos aspectos abordados (40\%) conforme mostra a Figura 6. Celnik \& Lebègue (2014) descrevem o surgimento do BIM como resultado de "um movimento internacional em favor de novas ferramentas colaborativas e da criação de um formato único de troca de dados, o formato IFC". A organização responsável por este movimento foi a International Alliance for Interoperability (IAI), atualmente reconhecida como Building SMART.

Os autores definem o sistema em dois formatos de troca de dados: 1. Closed BIM (adotados pela Autodesk, Bentley e Nemetschek); 2. Open BIM (standard IFC) que assegura a interoperabilidade e a durabilidade dos modelos tridimensionais. Ambos objetivam maior dinâmica entre as trocas constantes de dados e informações durante o desenvolvimento e a realização do projeto. Santa Catarina destaca-se como primeiro Estado do Brasil e aderir o Open BIM na esfera pública, propondo um fluxo de projeto transparente, com a troca de dados viabilizada independente do software utilizado, evitando-se, assim, a entrada múltipla de dados e os consequentes erros.

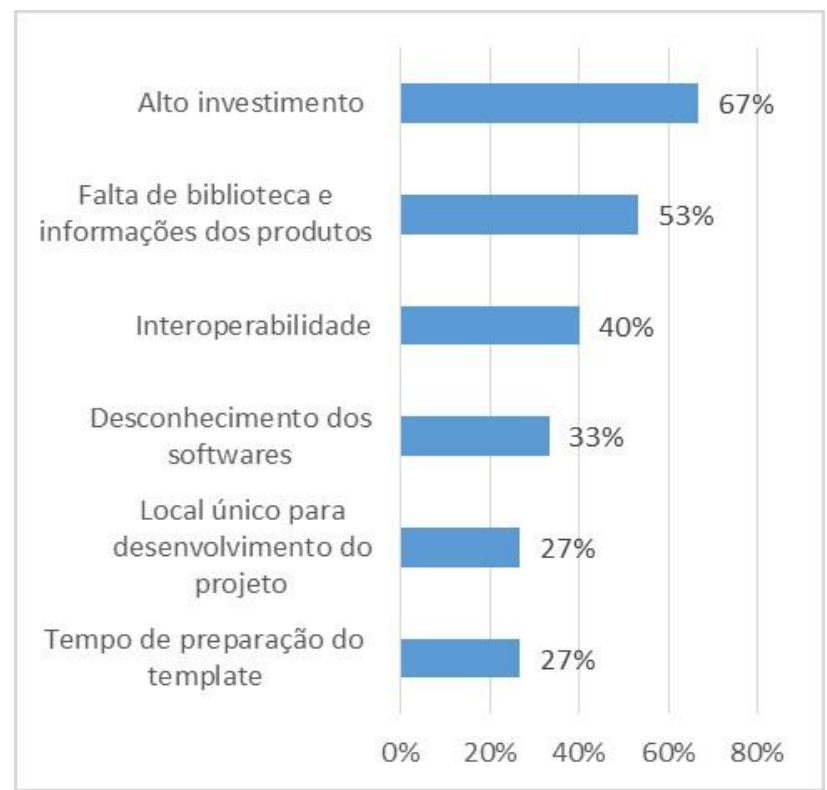

Figura 6: Desafios relacionados à tecnologia. Fonte: Os autores, 2017.
Além disso, outro ponto abordado foi o desconhecimento das ferramentas software (33\%). O entrevistado E3 acrescenta que "[...] a cada projeto surge uma nova demanda e uma nova funcionalidade é descoberta dentro de um software ou até mesmo um novo software para suprir tal demanda. Nesse ponto, os tutoriais online são uma grande fonte de aprendizagem, nos auxiliando a sanar dúvidas rápidas e problemas práticos do dia a dia".

Por fim, em quinto lugar apareceu o desafio de ter um local único para desenvolvimento do projeto e o longo tempo de preparação do template $(27 \%)$. O template consegue responder, em boa parte, o que é exigido em cada fase de projeto. E1 exemplifica: "[...] a gente preparou durante um bom tempo o nosso template, que é a organização do nosso material e da forma de trabalho dentro do BIM. Já temos configurado cada modo de visualização. Por exemplo, vai ter uma entrega e, dependendo do que é a etapa já está configurada. No estudo preliminar tem um nível de detalhamento, no anteprojeto e projeto legal tem outro então já está tudo configurado para atendimento dessas etapas. 0 entrevistado E2 complementa sobre a necessidade de estar sempre aprimorando o template e o desafio de "[...] como podemos simplificar o nosso modelo, mas sem perder a qualidade de informações para ele ficar leve e conseguir rodar."

\section{DISCUSSÃO}

Os resultados da pesquisa apontam os desafios enfrentados na implementação do BIM, a partir das perspectivas dos arquitetos atuantes na construção civil no mercado de Florianópolis-SC. Com base nos resultados obtidos e relacionando-os à literatura foram categorizados desafios que precisam ser superados para facilitar uma aplicação mais ampla da tecnologia BIM em todas as fases do ciclo de vida da edificação, e foram divididos em: fatores humanos, gestão, política e mercado e tecnologia.

Os desafios envolvem uma organização estratégica das empresas, a partir do redesenho dos processos e do fluxo de trabalho para a disseminação do BIM. Assim, sua implementação requer mudanças significativas na forma como as empresas de construção funcionam em todos os níveis do processo, redesenhando não só o fluxo de trabalho, mas também a forma de treinar a equipe, atribuição de responsabilidades e, principalmente, a proposição de um novo modelo colaborativo de trabalho.

Muitos são os agentes condutores desse processo. A pesquisa apontou que a esfera pública muito tem a desenvolver, especialmente na área de análise de projetos, para que possa assim impactar toda a cadeia e atuar como aceleradora da transformação. Do outro lado temos as construtoras e toda cadeia de fornecedores, que precisam contar mais com apoio das entidades, no sentido de promover discussões e materiais de qualidade para suporte nas implementações. Além disso, os profissionais que saem das Universidades e os pesquisadores devem representar fonte de inovação dentro desse contexto.

Por ser um processo ainda incipiente e de curva de aprendizagem lenta, apresentam-se muitos entraves. Mas, à medida que os usuários começarem a aprender 
sobre os benefícios do BIM para auxiliar em todo o ciclo da edificação, a metodologia será cada vez mais exigida. $\mathrm{E}$, à medida que $\mathrm{o}$ uso do BIM se intensifica, a colaboração entre as equipes de projetos aumenta, custos são reduzidos, diminuem-se desperdícios e o produto final construído tem mais qualidade, dentre outras melhorias que a tecnologia traz consigo.

Espera-se que os resultados desse estudo possam ajudar pesquisadores, profissionais e empresas do setor de construção a concentrar sua atenção e recursos nas questões importantes necessárias para apoiar a implementação da tecnologia BIM bem como promover discussões para alavancar sua disseminação.

\section{REFERÊNCIAS}

Aksamija, A. (2012). BIM-based building performance analysis: Evaluation and simulation of design decisions. Proceedings of the 2012 ACEEE Summer Study on Energy Efficiency in Buildings, Pacific Grove, CA, USA, 12-17.

Azhar, S., Nadeem, A., Mok, J. Y., \& Leung, B. H. (2008, August). Building Information Modeling (BIM): A new paradigm for visual interactive modeling and simulation for construction projects. In Proc., First International Conference on Construction in Developing Countries (Vol. 1, pp. 435446).

Bardin, L. (2009). Análise de conteúdo (Edição revista e actualizada). Lisboa: Edições, 70.

BIM-ASBEA, G. B. G. T. Guia Asbea Boas Práticas em BIM: Fascículo 1. 2013. São Paulo.

Carmona, J., \& Irwin, K. (2007). BIM: Who, what, how and why. Building Operating Management.

Cao, D., Wang, G., Li, H., Skitmore, M., Huang, T., \& Zhang, W. (2015). Practices and effectiveness of building information modelling in construction projects in China. Automation in Construction, 49, 113-122.

Celnik, O., \& Lebègue, E. (2014). BIM \& maquette numérique.

Eastman, C., Teicholz, P., Sacks, R., \& Liston, K. (2014). Manual de BIM: um guia de modelagem da informação da construção para arquitetos, engenheiros, gerentes, construtores e incorporadores. Bookman Editora.

Forgues, D., Staub-French, S., \& Farah, L. M. (2011). Teaching Building Design and Construction Engineering. Are we ready for the paradigm shift? Proceedings of the Canadian Engineering Education Association.

Glick, S., \& Guggemos, A. (2009, April). IPD and BIM: benefits and opportunities for regulatory agencies. In Proceedings of the 45th ASC National Conference, Gainesville, Florida, April(Vol. 2, No. 4).

Kassem, M., Kelly, G., Dawood, N., Serginson, M., \& Lockley, S. (2015). BIM in facilities management applications: a case study of a large university complex. Built Environment Project and Asset Management, 5(3), 261-277.

Kerosuo, H., Miettinen, R., Paavola, S., Mäki, T., \& Korpela, J. (2015). Challenges of the expansive use of Building Information Modeling (BIM) in construction projects. Production, 25(2), 289-297.

Khemlani, L., Papamichael, K., \& Harfmann, A. (2006). The potential of digital building modeling. August, 11, 2009.

Kymmell, W. (2007). Building Information Modeling: Planning and Managing Construction Projects with 4D CAD and Simulations (McGraw-Hill Construction Series): Planning and Managing Construction Projects with 4D CAD and Simulations. McGraw Hill Professional.

Manzione, L. (2013). Proposição de uma estrutura conceitual de gestão do processo de projeto colaborativo com o uso do BIM (Doctoral dissertation, Universidade de São Paulo).

Sacks, R., Korb, S., Barak, R. (2018). Building Lean, Building BIM. Improving Construction the Tidhar Way. New York, NY: Routledge.

Silva, A. S., Sorgato, M. J., Mazzaferro, L., Melo, A. P., \& Ghisi, E. (2014). Incerteza do método de simulação da NBR 155751 para a avaliação do desempenho térmico de habitações. Ambiente Construído, 14(4), 103-117.

Succar, B. (2009). Building information modelling framework: A research and delivery foundation for industry stakeholders. Automation in construction, 18(3), 357-375.

Yan, H., \& Demian, P. (2008). Benefits and barriers of building information modelling. 